\title{
Manejo anestésico para la separación quirúrgica de siamesas toraco-onfalopagas
}

\author{
Devonish N. ${ }^{1,2}$, Rubio J. ${ }^{1}$, Prado M. ${ }^{1}$, Romero R. ${ }^{1}$, Martínez R. ${ }^{1}$. \\ 1 Hospital Universitario de Maracaibo, Maracaibo, Venezuela. \\ 2 Universidad del Zulia, Maracaibo, Venezuela.
}

Se suministró anestesia general balanceada a gemelas siamesas toraco-onfalopagas de 8 meses de edad, producto del primer embarazo de 39 semanas, nacidas por cesárea de emergencia por procidencia de mano. Se les realizó laboratorio, valoración cardiovascular, ecocardiogramas, tomografía, etc. Ambas se premédica con Acetaminofen $15 \mathrm{mg}$ x Kg (24 horas antes) + Midazolam $1 \mathrm{mg}$ (1 hora antes). En quirófano fueron monitoreadas con ECG-ETO2-SCO2PANI+Sonda vesical. Paciente A (7 kg) se inicia con Midazolam $1 \mathrm{mg}+$ Fentanil $15 \mathrm{mgr}+$ Propofol $15 \mathrm{mg}+$ Rocuronio $8 \mathrm{mg}$ se procede a IOT. Con tubo \#4 s/balón. Mantenimiento: Remifentanil $20 \mathrm{mcg} / \mathrm{hora}+$ Sevofluorano 1-1,5 $\mathrm{CAM}+$ Rocuronio. Analgesia: Ketamina $2 \mathrm{mg}+$ Dipirona $200 \mathrm{mg}+$ Diclofenac $25 \mathrm{mg}$. Paciente B $(6 \mathrm{~kg}) \mathrm{se}$ inicia con MIdazolam $1 \mathrm{mg}+$ Fentanil $12 \mathrm{mg}$ + Propofol $10 \mathrm{mg}+$ Rocuronio $8 \mathrm{mg}$. Se procede a IOT con tubo \#4 s/balón. Mantenimiento: Remifentanil 18 mcghora + Sevofluorano 1-1.5 CAM + Rocuronio. Analgesia: Ketamina 2 mg + Dipirona $200 \mathrm{mg}+$ Diclofenac $25 \mathrm{mg}$. Ambas recibieron concentrado globular (2) c/u. Tiempo para la separación: 140 minutos. La paciente A ameritó aminas por bradicardia e hipotensión (adrenalina + dopamina). La paciente B presentó broncoespasmo moderado que cede con Hidrocortisana $100 \mathrm{mg}$ + Saglbutamol aerosol + sulfato de magnesio $24 \mathrm{mg}$. Duración total de la cirugía/anestesia: Paciente A: 305 minutos. Paciente B: 295 minutos. Ambas egresaron a la Unidad de Cuidados Intensivos Pediátricos.

Comentario/Discusión: Estadísticamente, los nacimientos de siamesas ocurren 1 vez cada 200.000, siendo mortinatos el 50\% de los casos y el 75\% son de sexo femenino. El manejo multidisciplinario es la clave para la supervivencia de ambas pacientes tras la separación. En el caso expuesto se presenta una aplicación concentrada de pautas anestésicas estandarizadas internacionalmente en cada etapa de la planificación y de la ejecución de la anestesia, logrando como resultado una separación segura y exitosa, y la supervivencia de ambas gemelas.

https://doi.org/10.25237/congresoclasa2019.32 